\title{
O ENSINO DE ASPECTOS HISTÓRICOS E FILOSÓFICOS DA QUÍMICA E AS TEORIAS ÁCIDO-BASE DO SÉCULO XX.
}

\author{
Aécio Pereira Chagas \\ Instituto de Química - Unicamp - CP 6154 - 13083-970 - Campinas - SP
}

Recebido em 4/12/98; aceito em 5/4/99

\begin{abstract}
THE TEACHING OF HISTORICAL AND PHILOSOPHICAL ASPECTS OF CHEMISTRY AND THE XX CENTURY'S ACID-BASE THEORIES. In this paper, an overview about philosophy of science, the concept of "theory" and some characteristics of a"good"theory (1- ordination and explanation of the facts, 2- proposal of problems, and 3- simplicity and funcionality) are initialy introduced. Following, some historical landmarks of acidity and basicity and a summary of the main acid-base theories of the $X X$ century (Arrhenius, solvent systems, protonic, electronic, Lux, Usanovich and ionotropic) are presented. Historical and conceptual relations between these theories are discussed and the three characteristics of a "good" theory are applied. The results showed that the protonic and eletronic theories are the "best". Some discussion of the implications to chemical education are presented too.
\end{abstract}

Keywords: acid-base theories; "good" theories; history and philosophy of chemistry.

\section{INTRODUÇÃO}

Uma tendência atual, no ensino da Química, tem sido a de enfatizar aos estudantes os aspectos sociais, num amplo sentido, associados ao desenvolvimento e aplicações desta Ciência. E aqui se inclui obviamente a História da Química. Independentemente de qualquer crítica que se possa fazer a esta tendência, não tem havido uma boa compreensão da mesma, e quando há, nem sempre a prática corresponde à proposta. Há por parte dos professores uma grande dificuldade em se lidar com a História da Química, o que é compreensível, pois, como se costuma dizer: "História da Química é mais difícil que Química". Entretanto, parte da dificuldade é devido aos assuntos que são escolhidos, muitas vezes relacionados com o desenvolvimento dos aspectos relativos à estrutura nuclear e eletrônica dos átomos, temas mais complexos do ponto de vista histórico.

Neste artigo pretende-se mostrar que há um outro tema histórico que pode ser apresentado aos estudantes sem grandes dificuldades: é o desenvolvimento das teorias ácido-base no século $\mathrm{XX}^{\mathrm{a}}$.

Além do lado histórico, é interessante que se discuta também alguns aspectos da disciplina denominada Filosofia da Ciência, que procura estudar as Ciências em seus aspectos filosóficos: lógico, epistemológico, estético, ético etc.. A Filosofia da Ciência procura também determinar se um dado conhecimento pode ser considerado científico ou não. Esta questão, que está longe de ser resolvida satisfatoriamente, é muito importante, face ao marcante impacto das ciências nas atividades humanas nos últimos duzentos anos. É comum ver na mídia expressões do tipo: "...foi cientificamente provado que o creme dental X combate as cáries..".. Da mesma forma como se apela aos recônditos desejos humanos do sexo, do poder etc., para se incrementar o consumo de alguma coisa, apela-se também para a Ciência, tendo em vista justamente sua importância adquirida nestes últimos tempos. Isto por si só já justifica o estudo da Filosofia da Ciência.

e-mail: aecio@iqm.unicamp.br

a Parte deste trabalho foi apresentado na 21ํㅡㄹ Reunião Anual da Sociedade Brasileira de Química, Poços de Caldas (MG). Livro de Resumos vol. 3, HQ-03.
Para se procurar uma caraterização da Ciência, a Filosofia utilizou (e utiliza) muito da História da Ciência, procurando analisar a produção do conhecimento tido como científico e verificar o que ele tem de comum e no que ele difere de outros tipos de conhecimento. Esta análise, de caráter mais lógico e epistemológico, acabou por mostrar que não existe propriamente alguma coisa que se pode chamar de "método científico", comum às Ciências maduras (Física, Química e Biologia), e mostrou, por outro lado, a importância das teorias na gênese deste conhecimento.

Esta importância epistemológica das teorias é um dos raros pontos de consenso entre os filósofos da ciência. Por teoria entende-se aqui, em uma primeira aproximação, um conjunto de conhecimentos devidamente organizados que procura ordenar, unificar, explicar, interpretar etc., um certo domínio de fenômenos ou acontecimentos. Na realidade a teoria é alguma coisa nova, qualitativamente diferente do simples arranjar desses fatos.

Porém, os filósofos da Ciência ainda estão longe de um consenso na maioria dos outros pontos. De algumas décadas para cá, surgiu também uma abordagem diferente, denominada "sociológica", que procura caracterizar também a Ciência como uma atividade humana, estudando a gênese do conhecimento através das relações entre aqueles que são reconhecidamente considerados "cientistas" pela sociedade, a estrutura dos grupos que estes formam etc. Parece que a abordagem conjunta destes vários aspectos, filosóficos e sociológicos, tem sido a mais promissora, quando eles convergem, para a caracterização da Ciência.

Esta parte da caracterização da Ciência, em geral, não será desenvolvida neste artigo. Para mais detalhes o leitor pode consultar as referências citadas, que foram selecionadas menos pela sua abrangência, mais por ser, em sua maioria, em língua portuguesa e portanto mais fácil de ser encontradas em bibliotecas e livrarias ${ }^{1-4}$.

Voltando-se à questão do creme dental e partindo-se do princípio de que o mesmo foi realmente testado no combate às cáries, estes testes podem ser considerados científicos ou não. Que critérios se pode adotar para tal? A resposta a esta questão passa pela caracterização do que é um conhecimento científico. Como já foi dito isto não é uma tarefa fácil e no presente caso qualquer tentativa de resposta é inócua, uma vez que não sabemos realmente como foram feitos os testes. No entanto uma anedota serve para o leitor pensar no assunto: Um certo 
cientista realizava, em seu laboratório, experiências com aranhas. Tomou de uma delas, colocou-a sobre a mesa e disse em bom tom: "Anda". E a aranha saiu andando. Pegou-a, cortou uma de suas pernas e colocou-a de novo sobre a mesa e tornou a dizer: "Anda". E a aranha saiu andando, meio mancando. Procedeu da mesma maneira com a segunda perna, com a terceira, até a sétima, sendo que a aranha ainda conseguia moverse. Após cortar a oitava disse mais uma vez: "Anda". E a aranha não andou. Concluiu então: "Aranha sem pernas não ouve". Os aracnologistas dizem que as pernas das aranhas são realmente sensores de vibrações muito sensíveis. Obviamente há alguma diferença entre sentir vibrações, e ouvir. Principalmente em ouvir um imperativo como "anda". Muitas "pesquisas científicas" são como esta, às vezes publicadas em revista de prestígio internacional, e até divulgadas pela mídia.

\section{CARACTERÍSTICAS DE UMA "BOA TEORIA"}

Mencionou-se acima a importância das teorias na Ciência. Como porém elas se comportam do ponto de vista do desenvolvimento histórico? A Ciência tem um caráter progressivo e as teorias vão se sucedendo, as "velhas" dando lugar às "novas". Costuma-se dizer que uma teoria ruim é suplantada por uma teoria boa. Como se realiza este processo? Quando uma teoria é aceita por uma comunidade de cientistas? Em outras palavras, quando uma teoria é "boa" ou "ruim"? As características de uma boa teoria é o que se pretende mostrar aqui, neste artigo, e obviamente a teoria que não satisfizer estes critérios será uma teoria ruim.

As idéias aqui apresentadas são uma síntese de várias visões sobre este assunto, existentes na literatura, e procurou-se realçar mais o aspecto didático, na História da Química, que propriamente o aspecto filosófico, apresentando-se uma visão esquemática e parcial do tema.

Pode-se considerar que uma teoria é "boa" quando satisfaz a três características:

C-1. Ordena e explica os fatos de seu domínio. Uma teoria tem dois aspectos. Um deles meio oculto, não explicitado, que considera um conjunto de fatos e não outros. É como se fosse um critério de classificação, separando de todos os acontecimentos que se sucedem, aqueles que vão interessar. Muitas concepções já estão na base deste aspecto, permitindo que um dado fato seja visto de uma determinada maneira e não de outras. O outro aspecto da teoria é o mais explícito, mais evidente, mais racional inclusive, que procura inicialmente classificar, ordenar os fatos de seu domínio (aqueles previamente selecionados), de acordo com critérios definidos, claros, e estes critérios muitas vezes se confundem com um corpo de princípios que compõe a própria teoria. Após deixar bem claro e mapeado o domínio dos fatos tratados, a teoria procura então explicar os fatos através de algum esquema, mecanismo, modelo, metáfora etc. Não vamos detalhar o significado disto, o que não importa no momento. O que importa é que a teoria possa explicar, mostrar racionalmente uma relação de causa $e$ efeito entre as entidades ou conceitos relativos aos fatos que ela ordenou em seu próprio domínio.

C-2. Propõe problemas. Como a Ciência é progressiva, está sempre crescendo, uma boa teoria deve contribuir para isto, alimentando os cientistas com problemas que possam ser resolvidos em seu âmbito. Por exemplo, a teoria atômica proposta por Dalton, considerava que as relações entre as massas dos elementos encontradas na análise química eram também as relações entre os pesos atômicos. A determinação acurada destes foi um dos problema mais importantes na Química do século XIX. Dentre os problemas que uma teoria pode propor, um tipo muito importante são aqueles que estão prevendo fatos novos, no âmbito da própria teoria, é claro. São as chamadas previsões. Estes fatos, quando encontrados, não apenas contribuem para este lado progressivo, mas corroboram, testificam a teoria. Muitos acham que este poder de previsão é uma das maiores forças da Ciência. Por exemplo, quando Mendeleiev apresentou sua Classificação Periódica, ele previu, com base na mesma, a existência de três novos elementos e sua posterior descoberta mostrou a importância e a certeza da Classificação.

C-3. Ser prática, simples, funcional. As teorias são para serem usadas. Se elas não atenderem a estas características não serão usadas para explicar, para resolver problemas, para prever. Elas também devem utilizar conceitos condizentes com sua época. Explicações "avançadas" para o seu tempo não têm utilidade. Por outro lado, muitas teorias já foram abandonadas por não explicarem satisfatoriamente os fatos de seu domínio, porém sua linguagem, seu esquema de raciocínio ainda permanecem em uso devido a esta funcionalidade. Por exemplo, a teoria do calórico, ou seja, a teoria que considera o calor como um fluido imponderável que se transfere para os corpos com diferentes temperaturas, foi abandonada após a primeira metade do século XIX. No entanto as equações de Fourier, concebidas dentro desta teoria e que permitem cálculos de transferência de calor, estão em uso e, em Nutrição, a concepção das "calorias ingeridas nos alimentos, e que são queimadas", ainda é de uso corrente. No vocabulário químico há palavras da época medieval: pureza, sublimação etc. (ver o item Origem de Alguns Termos e Alguns Fatos Históricos Importantes).

Outras características podem ser acrescentadas, porém, como já foi mencionado, não é nosso intento fazer uma "teoria das teorias", mas apenas fornecer um esquema didático para ser utilizado por professores e estudantes.

Enquanto uma teoria for "boa", ou seja, satisfizer as características acima, ela permanece em uso, podendo ser deixada de lado quando estas características tendem a diminuir. A maneira como uma teoria é apresentada e divulgada é também importante, principalmente por sua presença nos textos didáticos. O "polimento" dado à mesma pelos professores, geralmente contribui para um aumento de C-3. Vale a pena lembrar uma afirmação de Einstein: "A marcha da Ciência é mais determinada pelos autores dos livros didáticos que pelo trabalho daqueles que ganharam o prêmio Nobel" ${ }^{5}$.

\section{AS TEORIAS ÁCIDO-BASE: O QUE SIGNIFICAM}

Como será visto mais adiante, o que se pode chamar de comportamento ácido-base foi reconhecido há muito tempo. Desde que isto ocorreu os químicos têm elaborado teorias que procuram explicar este comportamento. Essas teorias procuram definir o que seja um ácido e uma base e como reagem, além de outros aspectos que podem ser considerados secundários. $\mathrm{O}$ interessante é que atualmente, segundo algumas teorias, grande parte das substâncias conhecidas apresentam este comportamento, o que torna o tema interessante e fundamental também para o estudo da Química. Do ponto de vista histórico este tema, a nosso ver, apresenta as seguintes vantagens:

As partes de seu desenvolvimento, que serão destacadas, ocorreram neste século, o que traz menos dificuldades no que se refere ao entendimento do contexto cultural da época. Tem um desenvolvimento praticamente linear com o tempo (caso raro), o que facilita muito o seu entendimento.

Pode ser correlacionada facilmente com a parte química propriamente dita, inclusive na parte experimental.

Permite discutir, com certa facilidade, o desenvolvimento das teorias científicas, inclusive nos aspectos lógicos e filosóficos, se isto for o caso.

Permite mostrar que a Química é a associação de uma teoria e uma prática, ou seja, um pensar em termos moleculares e um proceder empírico, fenomenológico, pois um mesmo fato pode ser interpretado de vários pontos de vista.

Cabe aqui também um parêntese a respeito do que estamos chamando de teorias ácido-base. Alguns autores preferem dizer definição, ao invés de teoria, pois em alguns casos tem-se definições do que seja um ácido e uma base dentro 
de uma teoria mais geral, como as definições de Arrhenius dentro de sua Teoria da Dissociação Eletrolítica ${ }^{6}$. Estes autores não deixam de ter razão, porém a nosso ver a simples definição tornou-se algo muito mais amplo com o passar do tempo, da mesma forma como determinadas hipóteses (como a hipótese de Avogadro) acabaram até por se tornar fatos, apesar de muitos ainda continuarem utilizando o nome de batismo. Utilizaremos a denominação de teoria para englobar a definição de ácido e base e o conjunto de idéias, conceitos, procedimentos, experimentais inclusive, etc., inerentes à própria teoria. Esta visão corresponde ao conceito de teoria apresentado na Introdução deste artigo.

Serão, a seguir, apresentados: origens de alguns termos e alguns fatos importantes antes do século XX, aspectos gerais do desenvolvimento das teorias ácido-base neste século, um breve sumário de cada uma das teorias, aspectos lógicos e filosóficos das mesmas.

\section{ORIGENS DE ALGUNS TERMOS E ALGUNS FATOS HISTÓRICOS IMPORTANTES}

Alguns dos termos que se utilizam ainda hoje têm sua origem na Antiguidade:

ÁCIDO: do latim acidus, a, um, significando azedo, ácido ${ }^{7}$. ÁLCALI: do árabe al qaliy, significando cinzas vegetais ${ }^{6}$. SAL: do latim sal, salis, significando sal marinho. Para Plínio, o Velho (sec. I DC), o sal é o sólido resultante da evaporação da água, o que obviamente inclui o sal marinho, e também outros materiais que podem ser assim obtidos.

BASE: termo mais recente, introduzido pelo francês Duhamel du Monceau em 1736, sendo depois adotado e popularizado por G. F. Rouelle $(1754)^{6}$.

Plínio, o Velho, o célebre naturalista romano supracitado, menciona, em seus escritos, a caustificação da soda, ou seja, a reação entre o carbonato de sódio natural (conhecido por natron, e hoje denominado vulgarmente de soda ou barrilha) e a cal (hidróxido de cálcio), em solução aquosa, precipitando carbonato de cálcio e ficando uma solução de hidróxido de sódio (a vulgar soda cáustica) ${ }^{7}$. A equação representativa é:

$\mathrm{Na}_{2} \mathrm{CO}_{3}(\mathrm{aq})+\mathrm{Ca}(\mathrm{OH})_{2}(\mathrm{aq})=\mathrm{CaCO}_{3}(\mathrm{~s})+2 \mathrm{Na}(\mathrm{OH})(\mathrm{aq})$

Robert Boyle, em 1664, publica, na Inglaterra, o livro "Experimental History of Colours", onde relata seu trabalho com as substâncias coloridas, cujas cores se alteram com a presença de ácidos ou álcalis. Dentre as substâncias que ele estuda estão o tornassol e o corante vermelho extraído do pau-brasil (Brazilwood). Interessante é que Boyle apresenta, também, resultados obtidos por estudiosos do século anterior ${ }^{8}$.

No século XVII, já se conhecia a reação:

ácido + álcali $=$ sal

tendo sido utilizada, por exemplo, por Glauber para preparar vários compostos?.

Em 1754, Rouelle, conforme mencionado acima, começa a utilizar o termo base, significando os álcalis $\left(\mathrm{Na}_{2} \mathrm{CO}_{3}, \mathrm{~K}_{2} \mathrm{CO}_{3}\right.$, $\mathrm{NaOH})$, as terras $(\mathrm{CaO}, \mathrm{MgO})$ e os metais (Fe, $\mathrm{Zn})$. As terras eram também denominadas cales ou cais (cal no singular $)^{6}$. Consequientemente passou a se ter:

ácido + base $=$ sal

W. Homberg, em 1699, realiza as primeiras tentativas de medir as quantidades relativas de ácidos e bases, porém somente em 1729, C. Geoffroy realiza a primeira titulação (soda, $\mathrm{Na}_{2} \mathrm{CO}_{3}$, com vários tipos de vinagre). W. Lewis, em 1767, utiliza pela primeira vez um indicador em uma titulação ${ }^{6,8}$.

Como parte de seu Sistema do Oxigênio, que englobava também uma teoria da combustão, A. Lavoisier, em 1789, afirmava que "o oxigênio é o princípio acidificante". Em outras palavras, dizia que todo ácido deveria ter oxigênio. Entretanto, já nesta época, C. Berthollet (1787), e depois H. Davy (1810), descreveram vários ácidos que não apresentavam o oxigênio: $\mathrm{HCN}, \mathrm{H}_{2} \mathrm{~S}, \mathrm{HCl}$ etc. 6 .

É interessante destacar aqui duas afirmações feitas no século XIX:

A. Ure, em 1823: "...não há um princípio [elemento] acidificador, nem critério absoluto da escala de força entre os diferentes ácidos ... [acidez e alcalinidade dependem mais] do modo como os constituintes estão combinados que da natureza dos constituintes em si" ${ }^{\prime \prime}$.

J. Liebig, em 1838: "ácidos são compostos de hidrogênio, nos quais o hidrogênio pode ser substituído por metais" ${ }^{\prime \prime}$.

Estas duas posições irão permear as discussões ácido-base no século XX, a de Ure, afirmando que o comportamento ácido-base é algo dependente do modo que os elementos estão combinados, da estrutura, como se diria hoje, e a de Liebig, atribuindo a um dado elemento, o hidrogênio, este comportamento ácido-base.

O séc. XIX marca também o desenvolvimento da Teoria Molecular e este conceito de Liebig é o que prevalece. Por que prevalece este conceito e não o de Ure? Estou certo que o leitor encontrará a resposta após a leitura deste artigo.

Estes aspectos da química ácido-base foram apenas para servir de preâmbulo ao que nos interessa. Muitos aspectos históricos e químicos interessantes foram deixados de lado.

\section{ASPECTOS GERAIS DAS TEORIAS ÁCIDO-BASE NO SÉCULO XX}

O desenvolvimento das teorias ácido-base, como o das outras teorias, se fez (e se faz) no sentido de procurar sistematizar e explicar o maior número possível de fatos químicos, bem como prever novos fatos e resolver outros problemas químicos ${ }^{\mathrm{b}}$. A primeira teoria a ser considerada é a teoria de Arrhenius (de

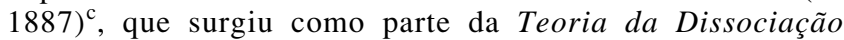
Eletrolítica e que abrangeu um grande número de fatos conhecidos e possibilitou o surgimento de várias linhas de pesquisa. À medida que estes novos resultados foram se acumulando, a teoria foi se mostrando incapaz de dar conta dos mesmos. Da crítica teoria de Arrhenius surgiram outras duas novas: a teoria protônica (1923) e a teoria dos sistemas solventes (1920). Estas por sua vez se desenvolveram e passaram pela mesma situação. Em 1923, Lewis apresentou a primeira proposta de sua teoria ácido-base, como parte de sua teoria do par eletrônico, criada para explicar a ligação química, que apesar de mais geral não consegue, na época, cativar a maioria dos químicos. Isto só foi possível ao ser reapresentada novamente, pelo próprio Lewis em 1938. Nesta mesma época surge a teoria de Lux (1939), interessante para sistemas envolvendo óxidos e sais fundidos, e a teoria de Usanovich (1939), que pretendeu ser uma teoria bastante geral, porém fracassou por uma série de circunstâncias. Em 1954, Lindqvist e Gutmann apresentaram a teoria ionotrópica, em que generalizaram as teorias protônicas, a do sistema solvente e a de Lux. Vamos fazer um breve resumo de cada uma delas, pois não haveria espaço para um desenvolvimento maior. O leitor interessado em maiores detalhes poderá consultar o excelente livro de Jensen ${ }^{6}$.

b Obviamente toda teoria quer ser "boa".

c Pode-se dizer que a Química do século XX começa com a teoria de Arrhenius. Alguns historiadores, como E. Hobsbawm, consideram que o século XIX inicia-se com a queda da Bastilha em 1784 e termina com o atentado de Saravejo, em 1914, iniciando-se aí o século XX, que termina na mesma cidade em 1991. Em outras palavras, o calendário não coincide necessáriamente com as épocas históricas. 


\section{Teoria de Arrhenius}

Segundo esta teoria ácido é toda substância que em água produz íons $\mathrm{H}^{+}$e base é aquela que produz $\mathrm{OH}^{-}$. A neutralização seria a reação entre estas duas espécies iônicas produzindo água:

$\mathrm{H}^{+}(\mathrm{aq})+\mathrm{OH}^{-}(\mathrm{aq})=\mathrm{H}_{2} \mathrm{O}(\mathrm{l})$

Note que esta definição de ácido é semelhante à de Liebig, apesar de estarem em um contexto um pouco diferente.

Esta teoria foi muito importante, pois além de dar conta de um grande número de fenômenos já conhecidos, provocou o desenvolvimento de várias linhas de pesquisa, inclusive contribuiu muito para se estabelecer as bases científicas da Química Analítica. Mencionemos alguns fatos: aplicação da lei de ação das massas a equilíbrios iônicos e a obtenção da lei de diluição de Ostwald (Ostwald, 1887); a equação de Nernst, que relaciona a força eletromotriz das pilhas com a concentração dos íons (Nernst, 1888-9); o eletrodo de hidrogênio e a determinação da concentração de íons $\mathrm{H}^{+}$(Le Blanc, 1893); o efeito tampão (Fernbach, 1900); o primeiro estudo quantitativo de um indicador (Friedenthal, 1904); determinação da constante de dissociação da água (Heydweller, 1909); o conceito de $\mathrm{pH}$ (Sørensen, 1909); extensão da teoria para a amônia líquida (Franklin, 1905) etc.. Apesar de todos estes avanços, desde o início a teoria mostrou-se restrita à água, sendo que em alguns casos foi possível estendê-la a outros solventes (como a amônia líquida), porém em outros não. Em sistemas sólidos, como sílica, argilas, etc., não havia possibilidade de se aplicá-la ${ }^{6,10,11}$.

\section{As Críticas de Werner}

No período de 1895 a 1911, Alfred Werner, o fundador da Química de Coordenação, teceu uma série de críticas às teorias ácido base: a de Liebig, ainda em uso corrente e a de Arrhenius. Esta última, fora do contexto da dissociação eletrolítica, poderia ser considerada igual à definição de Liebig. Werner chamava a atenção para a semelhança funcional da neutralização com outras reações:

$$
\begin{aligned}
& \mathrm{BF}_{3}+\mathrm{KF}=\mathrm{KBF}_{4} \\
& \mathrm{PtCl}_{4}+2 \mathrm{KCl}=\mathrm{K}_{2} \mathrm{PtCl}_{6} \\
& \mathrm{SO}_{3}+\mathrm{K}_{2} \mathrm{O}=\mathrm{K}_{2} \mathrm{SO}_{4} \\
& \mathrm{CO}_{2}+\mathrm{Na}_{2} \mathrm{O}=\mathrm{Na}_{2} \mathrm{CO}_{3}
\end{aligned}
$$

Werner reinterpretou o processo de neutralização, não como uma simples reação de adição, mas como uma reação de transferência, levando à formação de espécies coordenadas. As reações acima poderiam ser equacionadas $\operatorname{como}^{6}$ :

$$
\begin{aligned}
& \mathrm{BF}_{3}+\mathrm{KF}=\mathrm{K}^{+}+\left[\mathrm{BF}_{4}\right]^{-} \\
& \mathrm{PtCl}_{4}+2 \mathrm{KCl}=2 \mathrm{~K}^{+}+\left[\mathrm{PtCl}_{6}\right]^{2-} \\
& \mathrm{SO}_{3}+\mathrm{K}_{2} \mathrm{O}=2 \mathrm{~K}^{+}+\left[\mathrm{SO}_{4}\right]^{2-} \\
& \mathrm{CO}_{2}+\mathrm{H}_{2} \mathrm{O}=2 \mathrm{H}^{+}+\left[\mathrm{CO}_{3}\right]^{2-}
\end{aligned}
$$

\section{Teoria dos sistemas solventes}

Esta teoria começou a ser desenvolvida em 1905 por E. C. Franklin, principalmente para a $\mathrm{NH}_{3}$ líquida, e depois por vários outros pesquisadores, por generalização da teoria de Arrhenius. Pode-se dizer que é uma obra coletiva. Considera que todo solvente sofre uma auto-ionização, gerando um cátion (ácido) e uma base (ânion):

solvente = cátion + ânion
Ácido é tudo que faz aumentar a concentração do cátion característico do solvente e base é o que aumenta a concentração do ânion característico. A neutralização é a formação do solvente a partir destes cátions e ânions característicos.

$$
\begin{aligned}
& 2 \mathrm{H}_{2} \mathrm{O}=\mathrm{H}_{3} \mathrm{O}^{+}+\mathrm{OH}^{-} \\
& 2 \mathrm{NH}_{3}=\mathrm{NH}_{4}^{+}+\mathrm{NH}_{2}^{-} \\
& 2 \mathrm{SO}_{2}=\mathrm{SO}^{2+}+\mathrm{SO}_{3}{ }^{2-} \\
& 2 \mathrm{POCl}_{3}=\mathrm{POCl}_{2}^{+}+\mathrm{POCl}_{4}{ }^{-}
\end{aligned}
$$

Dezenas de solventes foram estudados, principalmente visando obter novas reações e novos compostos ${ }^{6,12}$.

\section{Teoria protônica}

Foi proposta em 1923, independentemente, por G. Lewis (E.U.A.), T. Lowry (Inglaterra) e J. Brønsted (Dinamarca), no entanto foi este último um dos que mais contribuíram para o desenvolvimento da mesma. Segundo esta teoria, ácido é um doador de prótons (seria o mesmo que o íon $\mathrm{H}^{+}$, o núcleo do hidrogênio, porém esta denominação é melhor, pois ajuda distinguir da teoria de Arrhenius) e base um receptor de prótons. A reação de neutralização seria uma transferência de prótons entre um ácido e uma base.

$\mathrm{AH}+\mathrm{B}=\mathrm{BH}+\mathrm{A}$

Exemplos:

$\mathrm{HCl}+\mathrm{NH}_{3}=\mathrm{NH}_{4}^{+}+\mathrm{Cl}^{-}$

$\mathrm{HAc}+\mathrm{H}_{2} \mathrm{O}=\mathrm{H}_{3} \mathrm{O}^{+}+\mathrm{Ac}^{-}$

$\mathrm{H}_{3} \mathrm{O}^{+}+\mathrm{OH}^{-}=2 \mathrm{H}_{2} \mathrm{O}$

$($ Ac $=$ acetato $)$. Esta teoria permitiu o desenvolvimento de estudos em sistemas fortemente ácidos (ácido sulfúrico como solvente), em sistemas sólidos, o desenvolvimento de indicadores para estes meios (Hammett, 1928); estudos de catálise ácido-base, com a respectiva equação de Brønsted (Brønsted, 1924); estudos de próton-afinidade em fase gasosa (propostas de Sherman 1932 e medições iniciadas apenas nos anos 60), etc. Apesar de alguns problemas internos, é uma teoria bastante utilizada e atual ${ }^{6,13}$.

\section{Teoria de Lux}

Proposta por H. Lux em 1939, é, em sua forma, semelhante à teoria protônica, considerando o ânion óxido $\left(\mathrm{O}^{2-}\right)$ a entidade transferida, ao invés do próton. Segundo Lux, ácido é um receptor de $\mathrm{O}^{2-}$ e base, um doador. Uma reação entre um óxido ácido $\left(\mathrm{CO}_{2}\right)$ e um óxido básico $(\mathrm{CaO})$ seria uma reação de neutralização:

$\mathrm{CO}_{2}+\mathrm{CaO}=\mathrm{Ca}^{2+}+\mathrm{CO}_{3}{ }^{2-}$

$\mathrm{SiO}_{2}+\mathrm{K}_{2} \mathrm{O}=2 \mathrm{~K}^{+}+\mathrm{SiO}_{4}^{2-}$

Mostrou-se bastante útil para tratar de reações envolvendo líquidos iônicos (sais e óxidos fundidos), reações estas que ocorrem na metalurgia, na fabricação de vidros e cerâmicas, nos sistemas geoquímicos etc. ${ }^{6,13}$.

\section{Teoria ionotrópica}

É uma generalização da teoria protônica, dos sistemas solventes e da de Lux, proposta por Lindqvist e Gutmann em 1954. As reações ácido-base podem ser formuladas como:

base + cátion característico $=$ ácido 
base $=$ ácido + ânion característico

Exemplos de cátions característicos: $\mathrm{H}^{+}$(Brønsted), $\mathrm{NH}_{4}{ }^{+}$ (em $\mathrm{NH}_{3}$ líquida), $\mathrm{SO}^{2+}$ (em $\mathrm{SO}_{2}$ líquido) etc.

Exemplos de ânions característicos: $\mathrm{OH}^{-}$(em água), $\mathrm{O}^{2-}$ (Lux), $\mathrm{SO}_{3}^{2-}$ (em $\mathrm{SO}_{2}$ líquido) etc. ${ }^{6,15}$.

Esta teoria é um "passar a limpo" das teoria anteriores. Pouco inovou em termos de gerar alguma linha de pesquisa (problemas, previsões etc.). Seus próprios autores fizeram posteriormente contribuições valiosas para o desenvolvimento da teoria eletrônica ${ }^{16,17}$.

\section{Teoria eletrônica}

Como conseqüência de sua teoria do par eletrônico para explicar as ligações químicas, G. N. Lewis, propõe uma teoria ácido base em 1923 (juntamente com a teoria protônica). Considerava que um ácido (A) é toda espécie química capaz de receber um par eletrônico e base (B), aquela capaz de doar um par eletrônico (representado por :). De uma maneira geral:

$$
\mathrm{A}+\mathrm{B}=\mathrm{A}: \mathrm{B}
$$

ácido base aduto, sal etc.

O composto $\mathrm{A}: \mathrm{B}$ recebe nomes diversos, conforme a circunstância: aduto, sal, complexo, complexo ácido-base, complexo doador-aceitador, etc ${ }^{\mathrm{d}}$. A eq. 25 representa uma reação genérica de neutralização.

Exemplos de reações de neutralização:

$$
\begin{aligned}
& \mathrm{H}^{+}(\mathrm{aq})+\mathrm{OH}^{-}(\mathrm{aq})=\mathrm{H}_{2} \mathrm{O}(\mathrm{l}) \\
& \mathrm{BF}_{3}+\mathrm{KF}=\mathrm{K}^{+}+\left[\mathrm{BF}_{4}\right]^{-} \\
& \mathrm{PtCl}_{4}+2 \mathrm{KCl}=2 \mathrm{~K}^{+}+\left[\mathrm{PtCl}_{6}\right]^{2-} \\
& \mathrm{SO}_{3}+\mathrm{K}_{2} \mathrm{O}=2 \mathrm{~K}^{+}+\left[\mathrm{SO}_{4}\right]^{2-} \\
& \mathrm{SiO}_{2}+\mathrm{K}_{2} \mathrm{O}=2 \mathrm{~K}^{+}+\mathrm{SiO}_{4}^{2-} \\
& \mathrm{HCl}+\mathrm{NH}_{3}=\left[\mathrm{NH}_{4}\right]^{+}+\mathrm{Cl}^{-} \\
& \mathrm{HAc}^{-} \mathrm{H}_{2} \mathrm{O}=\mathrm{H}_{3} \mathrm{O}^{+}+\mathrm{Ac}^{-} \\
& \mathrm{SO}^{2+}+\mathrm{SO}_{3}^{2-}=2 \mathrm{SO}_{2} \\
& \mathrm{CO}_{2}+\mathrm{CaO}^{2-} \mathrm{Ca}^{2+}+\mathrm{CO}_{3}^{2-} \\
& \mathrm{BF}_{3}+\mathrm{NH}_{3}=\mathrm{H}_{3} \mathrm{~N}^{2-} \mathrm{BF}_{3}
\end{aligned}
$$

Note que os exemplos são todas as reações anteriormente citadas, exceto a última (eq. 35) que agora é considerada uma reação ácido-base, não englobada pela teorias anteriores. $\mathrm{O}$ produto formado pode ser também representado por $\mathrm{H}_{3} \mathrm{~N} \rightarrow \mathrm{BF}_{3}$ (a seta, muitas vezes utilizada, indica o sentido da doação do par eletrônico) $)^{6,11}$.

Lewis não se apoiava somente em sua teoria do par eletrônico, mas também nas considerações funcionais de Werner, que considerava como reações de neutralização as reações exemplificadas nas eqs. 4 a 7 . Alguns aspectos históricos da teoria do par eletrônico podem ser encontrados em Davanzo e Chagas ${ }^{18} \mathrm{e}$, principalmente, nas referências citadas.

Interessa destacar que a teoria ácido base foi aplicada inicialmente no estudo de reações orgânicas (Lowry, Robinson, Ingold, Lapworth, na Inglaterra) e na Química de Coordenação

d Esta circunstância muitas vezes é mais de caráter "social" que químico, pois as denominações variam conforme a área da Química onde se empregam os termos.
(Sidwick, na Inglaterra). Surgiram então os termos doador e aceitador (Sidwick, 1927) e reagentes eletrofílicos e nucleofílicos (Ingold, 1933) ${ }^{6,19}$. Os termos cunhados por Ingold envolviam não apenas ácidos e bases, mas também oxidantes e redutores, generalizando assim os próprios conceitos de Lewis. Porém os diversos nomes e a generalidade excessiva não contribuíram para popularizar a teoria, ficando a forma generalizada por Ingold restrita ao estudo dos mecanismos de reações orgânicas e a denominação de Sidwick, ao campo da Química de Coordenação, não figurando em textos mais gerais ou introdutórios.

Em 1938, Lewis retorna ao tema ácido-base, apresentando uma conferência, depois publicada ${ }^{20}$, onde especifica os critérios fenomenológicos (ou macroscópicos) para o comportamento ácido base:

1) A reação entre um ácido e uma base (neutralização) é rápida.

2) Um ácido (ou uma base) pode deslocar um ácido (ou uma base) mais fraco de seus compostos.

3) Ácidos e bases podem ser titulados um com o outro por meio de indicadores.

4) Ácidos e bases são capazes de atuarem como catalisadores.

$\mathrm{Na}$ realidade estes critérios são uma síntese brilhante sobre a observação dos fenômenos até aquela época (e até hoje, talvez) conhecidos sobre o comportamento ácido-base. Ainda mais, neste artigo Lewis une estas observações fenomenológicas com a interpretação molecular (microscópica). Depois disto sua teoria "decolou", passou a ser vista em sua generalidade, como uma teoria unificadora, saindo do contexto restrito a que estava antes. Em 1940, nos E.U.A., já houve um grande simpósio reunindo pesquisadores e professores interessados ${ }^{12}$ e, a partir daí, muitos livros e artigos sobre o tema foram publicados; várias linhas de pesquisa se desenvolveram etc..

$\mathrm{O}$ desenvolvimento posterior da teoria eletrônica foi caracterizado principalmente pela sua quantificação. Vamos citar apenas alguns dos estudos desenvolvidos: o ácido etilenodiamintetraacético (EDTA), e outros agentes quelantes (G. Schwartzenbach, 1940-50), o estudo de efeitos estéricos em adutos (H. Brown, 1940), os conceitos de ácidos duros e moles (R. Pearson, 1963), as equações EC para prever as entalpias de formação de adutos ácido-base (R. Drago, a partir da década de 60), os conceitos de doabilidade ("donicidade") e aceitabilidade e suas medidas, bem como a correlação de fenômenos ácido-base e de óxido-redução (V. Gutmann, idem), a aplicação da Química Quântica às reações ácido-base (Klopman, idem), a Química Supramolecular (Lehn, a partir da década de 70) $6,17,21,22$

\section{Teoria de Usanovich}

Em 1939 o químico soviético M. Usanovich apresentou uma teoria muito geral através da qual pretendia generalizar todas as teorias existentes. Definia ácido como a espécie que reage com base para formar sais, doando cátions ou aceitando ânions ou elétrons, e base como a espécie que reage com ácidos para formar sais doando ânions ou elétrons, ou combinando com cátions ${ }^{6}$. Estas definições são de um certo modo semelhantes aos conceitos de reagentes eletrofílicos e nucleofílicos de Ingold.

Apesar de constar por algum tempo em vários textos, e ser eventualmente mencionada, praticamente não gerou nenhuma linha de pesquisa.

\section{RELAÇÕES CONCEITUAIS}

Nota-se que as teorias ácido-base que foram surgindo, apresentam uma tendência de cada uma generalizar a precedente e, o que é interessante, de não se contrapor, de querer negar frontalmente. Cada uma delas abarca um universo próprio de reações químicas que vai se alargando, se ampliando, procurando 
abranger cada vez mais os fenômenos químicos conhecidos e cada uma das teorias antigas vai se tornando caso particular das novas. A Figura 1 apresenta um diagrama de Veen que mostra a abrangência conceitual de cada uma das teorias. Este diagrama foi baseado na Figura 2.2 do livro de Jensen ${ }^{6}$.

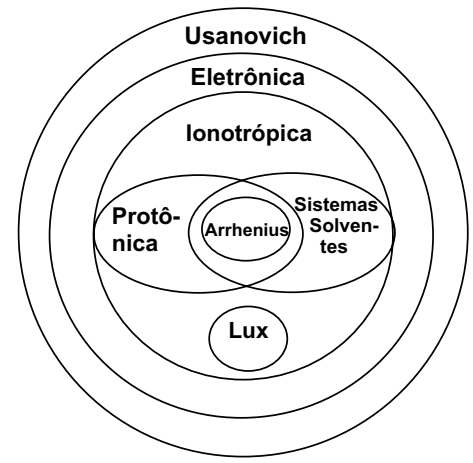

Figura 1. Diagrama de Veen mostrando as relações conceituais entre as teorias consideradas.

Outro aspecto interessante é o formalismo químico associado a cada uma das definições de neutralização. Na teoria de Arrhenius e na dos sistemas solventes, a neutralização é uma reação de síntese ou adição (eqs. 3, 12 - 16). Na teoria protônica, na de Lux e na ionotrópica, a neutralização é uma reação de dupla troca ou de transferência de alguma espécie química (eqs. 17 - 24). Na teoria eletrônica inicialmente a neutralização pode ser vista como uma síntese (eq. 25), porém nos exemplos citados o par eletrônico pode ser compartilhado (síntese, eqs. 26, 35) ou transferido (eqs. 27 - 29), conforme a estrutura eletrônica (ligação química) do produto resultante, superando a aparente oposição entre os dois esquemas formais.

A estrutura de todas as teorias é semelhante: comporta uma definição de ácido e de base, que apresenta uma simetria inversa, uma definição de reação de neutralização (a reação tipo entre um ácido e uma base) e, evidentemente, uma heurística e uma casuística $a^{\mathrm{e}}$ próprias da aplicação destes conceitos aos fatos já conhecidos e por conhecer ${ }^{\mathrm{f}}$. Sob este ponto de vista cada uma das teorias é bem diferente, mesmo quando uma é considerada um caso particular da outra. Além do formalismo das equações químicas, já mencionado, a aplicação das relações de equilíbrio (Lei de Ação das Massas) também se torna diferente. Da mesma forma, o papel do solvente em cada uma delas, uma vez que em umas ele é inerente (Arrhenius, sistemas solventes), ao passo que em outras o solvente pode ou não estar presente (protônica, eletrônica).

Algumas teorias apresentam algumas inconsistências lógicas internas, como por exemplo a definição de ácido na teoria protônica: ácido é um doador de prótons. O próton é também uma espécie química e cabe perguntar então se ele é um ácido ou uma base? A definição, como está, não pode responder, a não ser que se adicione uma ressalva à mesma. Entretanto isto não é um problema grave, uma vez que a experiência acaba por ressaltar que o próton é o ácido. Esta mesma inconsistência se manifesta nas outras teorias de transferência (Lux e ionotrópica) Também na teoria de Usanovich há uma tautologia

\footnotetext{
e Estamos entendendo estes vocábulos como: heurística é o conjunto de regras e métodos que conduzem à descoberta, à invenção e à resolução de problemas e casuística é a discussão e/ou análise dos casos dentro de um determinado contexto que podem levar à ampliação da compreensão deste contexto e/ou esclarecimento de outros casos.

f Note que o conceito de teoria formulado na Introdução, em primeira aproximação, esta sendo ampliado, com a inclusão de modos, métodos, de agir e pensar, próprios de cada teoria.
}

(círculo vicioso) nas definições de ácido e base, quando diz que "ácido é a espécie que reage com bases, ..." e "base é a espécie que reage com ácido, ...". Esta tautologia pode ser também removida, melhorando-se os enunciados.

Estas falhas lógicas são comuns nas teorias químicas e não constituem um impedimento para que sejam "boas". Pelo contrário, torna-as mais flexíveis, permitindo ampliações e aplicações a situações novas. Este ponto já foi bem ressaltado por Theobald ${ }^{23}$ e Hoffmann ${ }^{24}$.

\section{RELAÇÕES HISTÓRICAS}

Como foi apontado anteriormente (item As Teorias ÁcidoBase: O que Significam?), o desenvolvimento das teorias ácidobase é praticamente linear com o tempo. Isto pode ser melhor notado na Figura 2, baseada na Figura 2.3 do livro de Jensen ${ }^{6}$, que mostra as relações históricas das teorias expostas ao longo do século XX. São apresentadas duas vertentes. A primeira vertente (lado esquerdo da figura) está associada às idéias de Liebig, mencionada anteriormente (item 4), em que acidez está associada a um elemento ou espécie química. A segunda vertente (lado direito), está associada às idéias de Ure, associando a acidezbasicidade a uma característica estrutural. Note também que há uma espécie de convergência das duas vertentes, abandonando progressivamente estas características extremas e se aproximando umas das outras. A teoria ionotrópica já não se prende mais a uma espécie exclusiva, e a eletrônica, por outro lado, sai de um certo relativismo inerente às idéias de Ure, considerando um certo "elemento estrutural"- o par eletrônico ou a sua vacância ou orbital - responsável pela acidez-basicidade.

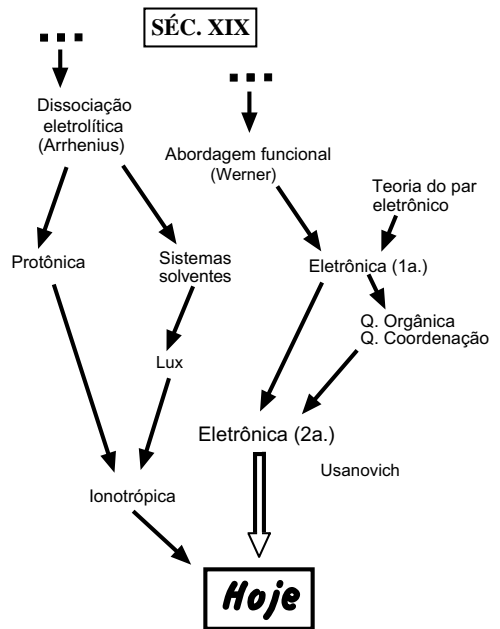

Figura 2. Diagrama mostrando as relações históricas das teorias ácido-base no séc. $X X$.

Pode-se considerar a Química como uma associação entre um fazer e um pensar. O fazer é o manuseio todo especial que o químico realiza com a matéria, transformando-a, modificando-a. O pensar é a interpretação, o raciocínio, a imaginação das transformações da matéria em termos de átomos e moléculas, ou seja, em termos da Teoria Molecular. A Química sempre foi assim, a associação de uma teoria com uma prática ${ }^{25}$. Na evolução da Química nota-se que a teoria tem sofrido mudanças bruscas com o passar do tempo, verdadeiras revoluções, porém a prática tem se modificado de forma mais ou menos contínua, às vezes mais rápida ou mais lentamente, porém sem grandes saltos. Vale aqui ressaltar os critérios fenomenológicos de Lewis ${ }^{20}$, que resumem toda a prática ácido-base, desde, pelo menos, o sec. XVII, com Boyle, independentemente de sua própria teoria. Em seu artigo, a apresentação clara e explícita de todos esses critérios e a 
subseqüente demonstração de que a teoria eletrônica era capaz de dar conta de todos os fenômenos, talvez tenha sido um fator importante para chamar a atenção sobre a mesma, fazendo com que ela se tornasse "popular" entre os químicos.

\section{AS "BOAS" CARACTERÍSTICAS DE CADA TEORIA}

Analisando-se o desenvolvimento histórico de cada uma das teorias, através das características de uma "boa" teoria apresentadas no início, observa-se que, a menos da teoria de Usanovich, todas satisfizeram C-1, C-2 e/ou C-3, em uma dada época.

A teoria de Arrhenius foi apresentada dentro a Teoria da Dissociação Eletrolítica e, do seu lançamento até por volta de 1910, satisfazia plenamente as três características. Porém, dificuldades com solventes não-aquosos, sólidos e outras situações, fizeram que deixasse de satisfazer as C-1 e C-2, dando lugar ao surgimento de outras teorias, sendo a primeira a teoria dos sistemas solventes. Esta é uma generalização da teoria de Arrhenius para sistemas não aquosos, satisfazendo C-1 e C-3, sendo que C-2 foi função do solvente, pois determinados solventes mostraram-se mais interessantes que outros.

A teoria protônica foi apresentada também como uma generalização da teoria de Arrhenius, porém abrangendo aspectos não tratados pela teoria dos sistemas solventes, e satisfazendo $\mathrm{C}-1, \mathrm{C}-2$ e $\mathrm{C}-3$.

A teoria eletrônica foi apresentada dentro da teoria do par eletrônico e esteve ligada, até 1938, aos aspectos estruturais e mecanísticos, principalmente dentro da Química Orgânica. Apresentava as três características, porém de maneira indireta. Após sua reapresentação tornou-se a teoria mais em evidência, satisfazendo plenamente C-1, C-2 e C-3.

A teoria do soviético Usanovich foi apresentada em uma ocasião infeliz, pouco antes da $2^{\mathrm{a}}$ Guerra Mundial, não tendo a devida divulgação e aperfeiçoamento. Apesar de pretender ser a mais geral das teorias ácido-base, não satisfazia C-1 devido às inconsistências internas, já mencionadas, e portanto acabou por não satisfazer C-2. Um outro aspecto é sua semelhança com os conceitos de Ingold, que começaram a se popularizar e a rivalizar com os mesmos. Além do mais, considerações funcionais relacionando reações ácido-base (transferência de pares eletrônicos) com reações de óxido-redução (transferência de elétrons não emparelhados) mostraram-se mais interessantes para um tratamento quantitativo que as definições amplas.

A teoria ionotrópica, generalização da teoria dos sistemas solventes e protônica, interessante quanto às C-1 e C-3, porém não intensa quanto à $\mathrm{C}-2$.

Atualmente, as três teorias mais destacadas são: Arrhenius, protônica e eletrônica, principalmente esta última. Esse destaque ainda para a de Arrhenius deve-se praticamente à C-3, justificando sua presença nos livros didáticos ou vice-versa. As teorias protônica e eletrônica continuam satisfazendo às três características.

A Tabela 1 resume estes resultados.

Tabela 1. As "boas" características das teorias ácido-base. O sinal + indica que a respectiva teoria satisfaz a determinada característica, o sinal - indica o contrário. O sinal +(-) indica que inicialmente a teoria satisfazia, porém depois deixou de satisfazer, \pm significa meio termo e o sinal ? indica dúvida.

\begin{tabular}{lcccc}
\hline Teoria & $\begin{array}{c}\mathrm{C}-1 \\
\text { (explicar) }\end{array}$ & $\begin{array}{c}\mathrm{C}-2 \\
\text { (problemas) }\end{array}$ & $\begin{array}{c}\mathrm{C}-3 \\
\text { (funcional) }\end{array}$ & $\begin{array}{c}\text { Presença nos } \\
\text { livros } \\
\text { didáticos }\end{array}$ \\
\hline Arrhenius & $+(-)$ & $+(-)$ & + & + \\
Sist. solventes & $+(-)$ & $+(-)$ & + & - \\
Protônica & + & + & + & + \\
Ionotrópica & + & - & + & \pm \\
Eletrônica & + & + & + & + \\
Usanovich & + & - & $-(?)$ & $+(-)$ \\
\hline
\end{tabular}

\section{CONCLUSÃO}

A respeito das teorias ácido-base, muitas considerações de caráter histórico e filosófico podem ainda ser feitas, porém destacaremos agora algumas de caráter mais pedagógico.

Por razões que no momento não vamos cuidar, muitos estudantes dos cursos médios trazem uma certa visão dualística, para não dizer maniqueísta, da realidade. Para eles as coisas "são" ou "não são", não há meio termo. Em algumas vezes isto funciona, porém na maioria sabemos que não. Muitos professores têm dificuldades em mudar um pouco a atitude destes alunos. O lado prático das teorias ácido-base auxilia o professor nesta tarefa, pois sua utilização inicial é dualística, sendo que depois o próprio aluno verifica que este dualismo não pode permanecer. Vejamos: inicialmente todas as substâncias ou são ácidos e bases ou não são nenhum dos dois. Isto pode ser testado com indicadores. Depois as substâncias podem ser classificadas em ácidos e bases, conforme seu comportamento perante os indicadores. E os produtos da reação? Uma teorias afirmam que são também ácidos e bases, outras não. E as substâncias anfóteras? Creio que isto pode ser bem aproveitado pelos professores ${ }^{26,27}$.

Por que se ensina a teoria de Arrhenius, se ela atualmente não satisfaz a C-1 e C-2? Ela é simples e funcional, satisfaz à C-3, conforme mencionado acima. No entanto, funcionalidade é algo também discutível, pois a teoria pode ser funcional, mas os cursos onde elas são ensinadas podem não ser, justamente pela sua presença. A teoria protônica, quando aplicada aos sistemas aquosos, envolvendo os íons usuais e suas respectivas reações, faz da teoria de Arrhenius um caso particular. Por que então não ensinar desta maneira? Será porque os livros são assim ou os livros são assim porque os professores assim ensinam? Felizmente o círculo vicioso está sendo quebrado, pois muitos livros editados recentemente trazem ainda a teoria de Arrhenius, porém como uma notícia histórica dentro de uma introdução ao tema, e o estudo dos ácidos e das bases em solução aquosa é feito de acordo com a teoria protônica. Oxalá a maioria dos textos passassem a seguir essa orientação.

\section{AGRADECIMENTO}

Agradeço ao Prof. Dr. Silvio S. Chibene, do Departamento de Filosofia, IFCH-Unicamp, pelas valiosas críticas e sugestões.

\section{REFERÊNCIAS}

1. Chalmers, A. F.; O que é Ciência Afinal? (2ª ed.); Ed. Brasiliense; São Paulo, 1993.

2. Idem; A Fabricação da Ciência; Ed. da Unesp; São Paulo, 1994.

3. Chrétien, C.; A Ciência em Ação; Papirus Ed.; Campinas, 1994.

4. Bachelard, G.; A Epistemologia; Edições 70; Lisboa, 1984.

5. Bent, H. A.; J. Chem Educ. 1980, 57, 395.

6. Jensen, W. B.; The Lewis Acid-base Concepts; John Wiley \& Sons; New York, 1980. Faria, E.; Dicionário Escolar Latino-português (6- ed.); FAE-MEC; Rio de Janeiro, 1994.

7. Rancke-Madsen, E.; The History of Indicators. In Indicators; Bishop, E., Ed.; Pergamon Press; Oxford, 1972.

8. Rheinboldt, H.; Selecta Chimica 1945, 3, 1. Reimpresso in Rheinboldt, H.; História da Balança; Nova Stella e Edusp; São Paulo, 1988.

9. Rocchicioli, C.; Le pH et sa Mesure; Presses Universitaires de France; Paris, 1967.

10. Servos, J. W.; Physical Chemistry from Ostwald to Pauling; Princeton University Press; Princeton (NJ), 1990.

11. Luder, W. F.; Zuffanti, S.; The Eletronic Theory of Acids and Bases (2nd. ed.); Dover Publications; New York, 1961.

12. Bell, R. P.; Acids and Bases; Methuen and Co. Ltd.; London, 1969. 
13. Paul, A.; Chemistry of Glasses, Chapman and Hall; London, 1982.

14. Gutmann, V.; Coordination Chemistry in Noaqueous Solvents; Springer-Verlag; Vienna, 1968.

15. Lindqvis, I.; Inorganic Adduct Molecules of OxoCompounds; Springer-Verlag; Berlin, 1963.

16. Gutmann, V.; The Donor-Acceptor Approach to Molecular Interactions; Plenun Press, New York, 1978.

17. Davanzo, C. U.; Chagas, A. P.; Quim. Nova 1993, 16, 152 e 262 (errata).

18. Nye, M. J.; From Chemical Philosophy to Theoretical chemistry; University of California Press, Berkeley (CA), 1993.
19. Lewis, G. N.; J. Franklin Inst. 1938, 226, 293.

20. Drago, R. S.; Matwiyoff, N. A.; Ácidos y Bases; Ed. Reverté; Barcelona, 1972.

21. Vögtle, F.; Supramolecular Chemistry; J. Wiley \& Sons, Chichester (UK), 1991.

22. Theobald, D. W.; Chem. Soc. Rev. 1976, 203.

23. Hoffman, R.; Angew. Chem. Int. Ed. Engl. 1987, 27, 1593. Há uma tradução portuguesa em Química 1993, 50, 44.

24. Chagas, A. P.; Como se Faz Química (2ª ed.); Editora da Unicamp; Campinas (1992).

25. Finster, D. C.; J. Chem Educ. 1989, 66, 659.

26. Philips, P. S.; Pennington, M.; Hall, R.; Educ Chem. 1998, 35,130 . 